\title{
Is direct consultant supervision of all trauma laparotomies necessary?
}

\author{
R Weale, ${ }^{1}$ VY Kong, ${ }^{2}$ J Blodgett, ${ }^{3}$ GV Oosthuizen, ${ }^{1}$ JL Bruce, ${ }^{2}$ W Bekker, ${ }^{2}$ V Manchev, ${ }^{2}$ GL Laing, ${ }^{2}$ DL Clarke ${ }^{2,4}$ \\ ${ }^{1}$ Department of General Surgery, Wessex Deanery, United Kindgom \\ ${ }^{2}$ Pietermaritzburg Metropolitan Trauma Service, Department of Surgery, University of KwaZulu-Natal, Durban, South Africa \\ ${ }^{3}$ Department of Epidemiology, PhD student, University College London \\ ${ }^{4}$ Department of Surgery, University of the Witwatersrand, Johannesburg, South Africa
}

Corresponding author: Dr Ross Weale (rossweale@doctors.org.uk)

Introduction: This study examines the nature of trauma laparotomies performed primarily by trainees and those performed under the direct supervision of a consultant.

Materials and Methods: A retrospective review was undertaken at the Pietermaritzburg Metropolitan Trauma Service (PMTS), South Africa. All patients who underwent a trauma laparotomy were included. Admission physiology, organ injury and outcome were assessed. Statistical comparison using STATA was performed. Chi-squared analysis was used for categorical variables and unpaired T-test for physiology.

Results: A total of 562 patients for trauma laparotomy were identified. Ninety percent (506/562) were male and the mean age was 30 years. The in hospital mortality was 7\% (40/562). A consultant was present at 35\% of cases (197/562). Consultantlead operations were found to have a higher rate of mortality $16 \%$ vs $2 \%(32 / 197$ vs 8/365: p < 0.001$)$ and ICU $45 \%$ vs $25 \%$ $(89 / 197$ vs 91/365: $\mathrm{p}<0.001)$ than trainee only.

Significant differences in many parameters of admission physiology were identified. Consultant-lead procedures had a higher lactate (3.7 vs 2.9: p 0.0043), respiratory rate (RR) (22 vs 20: p 0.0005), heart rate (HR) (102 vs 96: p 0.0035) and a lower systolic blood pressure (SBP) (115 vs 122: p 0.0001) diastolic blood pressure (DBP) (69 vs 73: p 0.0350) pH (7.34 vs 7.36: $\mathrm{p}$ 0.0216) base excess $(\mathrm{BE}, \mathrm{mEq} / \mathrm{L})\left(-4.1 \mathrm{vs}-2.5: \mathrm{p}\right.$ 0.0036) and bicarbonate $\left(\mathrm{HCO}_{3}, \mathrm{mEq} / \mathrm{L}\right)(21.3 \mathrm{vs} 22.5: \mathrm{p} 0.0043)$ than trainee only procedures. Consultants were more likely to be called in for a gunshot than a stab wound ( $\mathrm{p}<0.001)$. Of the solid organ injuries, consultants are more likely to be called in for cases with liver injury $23 \%$ vs $16 \%$ (45/197 vs 58/365: p 0.005) and pancreatic injury 15\% vs 3\% (30/197 vs 11/365: p < 0.001).

Conclusion: Trainees can safely undertake a subset of trauma laparotomies. However, patients with deranged physiology and complex hepatobiliary injuries should be operated on directly by a consultant.

\section{Introduction}

Surgical training has changed dramatically over the last three decades and is often described as being in a state of crisis. Lifestyle issues and the changing demographics of junior doctors have been blamed for the relative decrease in applicants for general surgical training programs. There has been on-going fragmentation and sub-specialisation of surgery with a loss of the true generalist. Increasingly junior doctors are choosing careers in non-surgical fields, or if they do choose a surgical career it is in the sub-specialities rather than in general surgery itself. In addition, a number of trends have combined to decrease the level of exposure of junior doctors and trainees to emergency general surgery. The improved efficacy of medical and non-operative treatment for many common surgical conditions has reduced the need for emergency surgery and minimal access surgery has decreased the need for laparotomy. This is reflected by the observation that whilst we have developed excellence in elective surgical sub-specialties we have tended to achieve only competence in emergency care. One of the positive effects of the patient safety movement is that it has focused attention on outcomes for emergency surgery. As a result many health authorities in the USA and United Kingdom have moved towards a situation of direct specialist presence at all major operations such as laparotomy. There is a counter argument that these increased levels of supervision serve to negatively impact on trainees' confidence and technical ability and that such an approach fails to prepare trainees adequately to be consultants themselves. 
Whilst South Africa is affected and influenced by global trends in surgical education, there are a number of factors that make the South African situation different to that in high income countries (HICs). The excessively high level of trauma in the country means that the need for emergency surgery remains high. In addition, the perennial discrepancy between the burden of disease and the resources available to manage it means that moving towards a situation where all emergency surgery is directly supervised by a specialist is difficult to achieve. The training system in South Africa relies on the selective direct supervision of emergency surgery. Trainees triage and resuscitate patients and operate on select cases autonomously. This is done in close communication with a consultant who will directly supervise select cases. In light of this, we set out to review our experience with laparotomy for trauma. We aimed to compare cases primarily performed by trainees and those performed under the direct supervision of a consultant in order to develop an evidence base to help us refine the algorithms which underpin our approach to technical training.

\section{Pietermaritzburg Metropolitan Trauma Service (PMTS)}

The province of Kwa-Zulu Natal (KZN) is on the eastern seaboard of South Africa. Pietermaritzburg is the capital city and is situated one hour inland from the urban conurbation of Durban. A million people reside in the city of Pietermaritzburg. The PMTS provides definitive trauma care to the city of Pietermaritzburg, as well as to the western third of the province. The PMTS covers a total catchment population of over three million people. It is also one of the largest academic trauma centres within the province. Approximately 3000 trauma patients are admitted per year, with around $50 \%$ having sustained penetrating trauma. The PMTS uses an electronic trauma registry - the Hybrid Electronic Medical Registry (HEMR). Ethics approval for this study and for maintenance of the HEMR was formally endorsed by the Biomedical Research Ethics Committee (BREC) of the University of Kwa-Zulu Natal (reference: BE 207/09 and BCA 221/13).

\section{Materials and Methods}

A retrospective review was undertaken at the Pietermaritzburg Metropolitan Trauma Service (PMTS), South Africa. All patients who underwent a trauma laparotomy were included. Admission physiology, organ injury and outcome were assessed. Four comprehensive scores were calculated and compared between both groups, including: PATI (penetrating abdominal trauma index), AIS-abdomen and AIS-chest (abbreviated injury scale), and ISS (injury severity score). Complications were also compared across both groups. Statistical comparison using STATA was performed. Chisquared analysis was used for categorical variables and unpaired T-test for continuous variables.

\section{Results}

A total of 562 patients underwent a trauma laparotomy at Greys' Hospital between December 2012 and July 2015. Ninety percent (506/562) were male and the mean age was 30 years. The in hospital mortality was 7\% (40/562). A consultant was present at $35 \%$ of cases (197/562) (Table 1). Consultantlead operations were found to have a higher rate of mortality $16 \%$ vs $2 \%(32 / 197$ vs $8 / 365: p<0.001)$ and ICU $45 \%$ vs $25 \%$ $(89 / 197$ vs $91 / 365: p<0.001)$ than trainee only (Table 2$)$.

Table 1: Demographics and physiology of patients undergoing trauma laparotomy

\begin{tabular}{|c|c|}
\hline$n=562$ & Table 1 \\
\hline \multicolumn{2}{|l|}{ Mean } \\
\hline Age years $( \pm S D)$ & $30( \pm 11)$ \\
\hline \multicolumn{2}{|l|}{$\operatorname{Sex}(\%)$} \\
\hline $\mathrm{F}$ & $56(10)$ \\
\hline M & $506(90)$ \\
\hline \multicolumn{2}{|l|}{ Physiology $( \pm S D)$} \\
\hline $\mathrm{SpO}_{2}$ & $95.3( \pm 5.1)$ \\
\hline RR & $21( \pm 6)$ \\
\hline HR & $98( \pm 22)$ \\
\hline SBP & $120( \pm 20)$ \\
\hline DBP & $71( \pm 17)$ \\
\hline $\mathrm{pH}$ & $7.36( \pm 0.11)$ \\
\hline $\mathrm{pO}_{2}$ & $10.8( \pm 6.3)$ \\
\hline $\mathrm{pCO}_{2}$ & $5.2( \pm 1.2)$ \\
\hline $\mathrm{BE}$ & $-3.0( \pm 6.5)$ \\
\hline $\mathrm{HCO}_{3}$ & $22.1( \pm 4.6)$ \\
\hline Lac & $3.2( \pm 3.0)$ \\
\hline \multicolumn{2}{|l|}{ Mechanism (\%) } \\
\hline Penetrating & $450(80)$ \\
\hline GSW & $163(29)$ \\
\hline SW & $287(51)$ \\
\hline Blunt & $112(20)$ \\
\hline \multicolumn{2}{|l|}{ Outcome (\%) } \\
\hline Death & $40(7)$ \\
\hline ICU & $180(32)$ \\
\hline \multicolumn{2}{|l|}{ Complications (\%) } \\
\hline Respiratory & $51(9)$ \\
\hline Wound & $50(9)$ \\
\hline Renal & $27(5)$ \\
\hline Neurological & $4(0.7)$ \\
\hline Cardiac & $3(0.5)$ \\
\hline $\begin{array}{l}\text { F: female M: male } \mathrm{S} \\
\text { respiratory rate HR: he } \\
(\mathrm{mmHg}) \mathrm{DBP} \text { : diastolic bl } \\
\text { pressure of oxygen/carbon } \\
\mathrm{HCO}_{3} \text { : bicarbonate (mEq/ } \\
\text { wound } \mathrm{SW} \text { : stab wound } \mathrm{IC}\end{array}$ & $\begin{array}{l}\text { on haemaglobin RR: } \\
\text { stolic blood pressure } \\
\mathrm{nHg} \text { ) } \mathrm{pO}_{2} / \mathrm{pCO} \text { : partial } \\
\text { : base excess ( } \mathrm{mEq} / \mathrm{L} \text { ) } \\
\text { amol/L) GSW: gunshot } \\
\text { unit }\end{array}$ \\
\hline
\end{tabular}


Table 2: Comparison of physiology, mechanism, organ injury and outcome of patients undergoing trauma laparotomy by consultant vs non-consultant. Physiology is compared using unpaired T-test. The remainder by chi-squared analysis.

\begin{tabular}{|c|c|c|c|}
\hline & Consultant & Non-consultant & p value \\
\hline$n(\%)$ & $197(35)$ & $365(65)$ & \\
\hline \multicolumn{4}{|c|}{ Physiology } \\
\hline $\mathrm{SpO}_{2}$ & $94.9( \pm 6.5)$ & $95.6( \pm 3.9)$ & 0.1396 \\
\hline $\mathrm{RR}$ & $22( \pm 7)$ & $20( \pm 6)$ & 0.0005 \\
\hline HR & $102( \pm 23)$ & $96( \pm 21)$ & 0.0035 \\
\hline SBP & $115( \pm 21)$ & $122( \pm 19)$ & 0.0001 \\
\hline DBP & $69( \pm 19)$ & $73( \pm 16)$ & 0.0350 \\
\hline $\mathrm{pH}$ & $7.34( \pm 0.13)$ & $7.36( \pm 0.10)$ & 0.0216 \\
\hline $\mathrm{pO}_{2}$ & $10.8( \pm 5.6)$ & $10.7( \pm 6.5)$ & 0.9601 \\
\hline $\mathrm{pCO}_{2}$ & $5.1( \pm 1.2)$ & $5.3( \pm 1.1)$ & 0.1014 \\
\hline $\mathrm{BE}$ & $-4.1( \pm 6.9)$ & $-2.5( \pm 6.3)$ & 0.0036 \\
\hline $\mathrm{HCO}_{3}$ & $21.3( \pm 5.3)$ & $22.5( \pm 4.3)$ & 0.0023 \\
\hline Lac & $3.7( \pm 3.5)$ & $2.9(2.8)$ & 0.0043 \\
\hline \multicolumn{4}{|c|}{ Mechanism (\%) } \\
\hline Penetrating & $152(77)$ & $300(82)$ & \multirow{2}{*}{0.1988} \\
\hline Blunt & $45(23)$ & $66(18)$ & \\
\hline GSW & $73(37)$ & $88(24)$ & \multirow{2}{*}{$<0.001$} \\
\hline SW & $79(40)$ & $212(58)$ & \\
\hline \multicolumn{4}{|c|}{ Organ injury (\%) } \\
\hline Liver & $45(23)$ & $58(16)$ & 0.005 \\
\hline Spleen & $24(12)$ & $329(9)$ & 0.317 \\
\hline Kidney & $22(11)$ & $18(5)$ & 0.019 \\
\hline LB & $50(25)$ & $91(25)$ & 0.973 \\
\hline SB & $67(34)$ & $146(40)$ & 0.184 \\
\hline Stomach & $41(21)$ & $58(16)$ & 0.109 \\
\hline Pancreas & $30(15)$ & $11(3)$ & $<0.001$ \\
\hline Diaphragm & $40(20)$ & $69(19)$ & 0.720 \\
\hline \multicolumn{4}{|c|}{ Outcome } \\
\hline Death & $32(16)$ & $8(2)$ & $<0.001$ \\
\hline ICU & $89(45)$ & $91(25)$ & $<0.001$ \\
\hline Time of op (min) & $111( \pm 60)$ & $92( \pm 40)$ & $<0.001$ \\
\hline \multicolumn{4}{|c|}{ Complications (\%) } \\
\hline Respiratory & $20(10)$ & $31(8)$ & 0.514 \\
\hline Wound & $19(10)$ & $31(8)$ & 0.647 \\
\hline Renal & $12(6)$ & $15(4)$ & 0.295 \\
\hline Neurological & $2(1)$ & $2(0.5)$ & 0.530 \\
\hline Cardiac & $2(1)$ & $1(0.3)$ & 0.250 \\
\hline \multicolumn{4}{|c|}{ Score $( \pm S D)$} \\
\hline PATI & $16( \pm 14)$ & $10( \pm 8)$ & $<0.001$ \\
\hline AIS-abdomen & $3.12( \pm 1.14)$ & $2.82( \pm 1.01)$ & 0.001 \\
\hline AIS-chest & $0.60( \pm 1.2)$ & $0.48( \pm 1.0)$ & 0.189 \\
\hline ISS & $14( \pm 9)$ & $11( \pm 7)$ & $<0.001$ \\
\hline
\end{tabular}

$\mathrm{SpO}_{2}$ \% saturation haemaglobin RR: respiratory rate HR: heart rate SBP: systolic blood pressure (mmHg) DBP: diastolic blood pressure $(\mathrm{mmHg}) \mathrm{pO}_{2} / \mathrm{pCO}_{2}$ : partial pressure of oxygen/carbon dioxide $(\mathrm{kPa}) \mathrm{BE}$ : base excess $(\mathrm{mEq} / \mathrm{L}) \mathrm{HCO}_{3}$ : bicarbonate $(\mathrm{mEq} / \mathrm{L}) \mathrm{Lac}$ : lactate $(\mathrm{mmol} / \mathrm{L})$ GSW: gunshot wound SW: stab wound LB: large bowel SB: small bowel ICU: intensive care unit PATI: penetrating abdominal trauma index AIS: abbreviated injury scale ISS: injury severity score 
Significant differences in many parameters of admission physiology were identified. Consultant-lead procedures had a higher lactate (3.7 vs 2.9: p 0.0043), respiratory rate (RR) (22 vs 20: p 0.0005), heart rate (HR) (102 vs 96: p 0.0035) and a lower systolic blood pressure (SBP) (115 vs 122: p 0.0001) diastolic blood pressure (DBP) (69 vs 73: p 0.0350) $\mathrm{pH}$ (7.34 vs 7.36: $\mathrm{p}$ 0.0216) base excess (BE, $\mathrm{mEq} / \mathrm{L})(-4.1$ vs -2.5: $\mathrm{p}$ 0.0036) and bicarbonate $\left(\mathrm{HCO}_{3}, \mathrm{mEq} / \mathrm{L}\right)(21.3$ vs 22.5 : p 0.0043 ) than trainee only (Table 2), and were more likely to be called in for a gunshot mechanism than stab wound $(\mathrm{p}<0.001)$.

Of the solid organ injuries, consultants are more likely to be called in for cases with liver injury $23 \%$ vs $16 \%$ (45/197 vs 58/365: p 0.005) and pancreatic injury $15 \%$ vs $3 \%$ (30/197 vs 11/365: $\mathrm{p}<0.001)$. There were highly statistically significant differences comparing consultant vs non-consultant procedures for PATI $(16( \pm 14)$ vs $10( \pm 8) \mathrm{p}<0.001)$, AISabdomen $(3.12( \pm 1.14)$ vs $2.82( \pm 1.01)$ p 0.001$)$, and ISS $(14( \pm 9)$ vs $11( \pm 7) \mathrm{p}<0.001)$. There was not a statistically significant difference in AIS-chest across groups.

\section{Discussion}

Although major elective surgery is routinely undertaken with extremely low mortality rates the same cannot be said for emergency operations. The UK Emergency Laparotomy Network (ELN), detailed prospective outcome data for 1853 patients from across the UK who were subjected to an emergency laparotomy. That report showed that emergency laparotomy in the UK is associated with a high mortality rate. The unadjusted 30 -day mortality rate was $14.9 \%$, across the board. ${ }^{1}$ In those over 70 years it increased to just under a quarter. ${ }^{2}$ There are a number of reasons for this. Emergency operations are performed under more adverse circumstances than major elective work, ${ }^{3}$ the level of staff managing emergency work is heterogeneous and the nature of the pathology uncertain. ${ }^{4,5,6}$ Emergency conditions may present both technical and resuscitation related challenges. ${ }^{7,8}$ In addition, pre-existing co-morbidities may complicate management. Trauma laparotomy is an emergency procedure to which all the above factors are directly applicable.

South Africa is a middle-income country (MIC) with a well-established surgical training system. ${ }^{9,10}$ Although the eight medical schools currently produce approximately 25 surgeons per year, it is estimated that the country needs to produce at least 50 surgeons per year to provide adequate access to surgical care for the entire population. ${ }^{11}$ In light of this workforce shortage it is unlikely that we will be able to move towards a system in which each trauma laparotomy is supervised directly by a specialist. Our data suggests that this is not necessary for every case and that a selective approach may well be appropriate. A high risk procedure has been variously defined as one associated with a mortality rate of between $5-10 \% .^{12,13,14}$ By these definitions, the outcome for trainee-lead operations seems to be acceptable at our institution as the associated mortality rate was 2 percent. It would appear that a well-defined cohort of patients who require trauma laparotomy can be operated on safely by surgical trainees. However, there is a definite cohort in whom this is not safe. This is for patients with deranged physiology and major hepatobiliary injuries and the cohort of patients in which there was direct specialist involvement in the operation had significantly worse PATI, AIS-abdomen and ISS than the cohort operated on by trainees. This would suggest that we need to target our quality improvement efforts on this cohort of patients.

There are a number of limitations to this study and there are several factors which cannot be investigated adequately using this retrospective audit. It remains unclear in the cohort of patients in which there was direct specialist supervision at which point in the surgery the specialist became involved in the operative care. In addition, there needs to be some modelling to take account of individual trainee experience and skill as this will also undoubtedly impact on outcome. ${ }^{15}$ Further work must focus on the use of preoperative scores designed to identify these high risk patients preoperatively and to ensure that there is specialist involvement early in the operative management of these patients.

\section{Conclusion}

Trainees can safely undertake a subset of trauma laparotomies. However patients with deranged physiology and complex hepatobiliary injuries should be operated on directly by a consultant. Further work should focus on developing scoring systems to predict such patients prior to surgery and to ensure that there is direct specialist involvement prior to commencement of any operation in these patients.

\section{Compliance with ethical standards}

All authors have no conflict of interest to declare.

For this type of retrospective study, formal consent is not required

\section{REFERENCES}

1. Barrow E, Anderson I, Varley S, Pichel A, Peden C, Saunders $\mathrm{D}$, et al. Current UK practice in emergency laparotomy. Ann R Coll Surg Engl. 2013;95(8):599-603.

2. Watt D, Wilson M, Shapter O, Patil P. 30-Day and 1-year mortality in emergency general surgery laparotomies: an area of concern and need for improvement? Eur J Trauma Emerg Surg. 2014;41(4):369-74.

3. Mak M, Hakeem A, Chitre V. Pre-NELA vs NELA - has anything changed, or is it just an audit exercise? Ann R Coll Surg Engl. 2016;98(8):554-9.

4. Saunders D, Murray D, Pichel A, Varley S, Peden C. Variations in mortality after emergency laparotomy: the first report of the UK Emergency Laparotomy Network. Br J Anaesth. 2012;109(3):368-75.

5. Schneider C, Tyler L, Scull E, Pryle B, Barr H. A case-control study investigating factors of preoperative delay in emergency laparotomy. Int J Surg. 2015;22:131-5.

6. Steenkamp C, Kong V, Clarke DL, Sartorius B, Bruce JL, Laing GL, et al. The effect of systematic factors on the outcome of trauma laparotomy at a major trauma centre in South Africa. 
Ann R Coll Surg Engl. 2017:99(7);540-4.

7. Emergency General Surgery: The future. A consensus statement. Association of Surgeons of Great Britain and Ireland; 2007. Available from: http:// asgbi.org.uk/en/publications/consensus statements.cfm

8. Mason M. 'The NCEPOD Method' - How the National Confidential Enquiry into Patient Outcome and Death designs and delivers national clinical outcome review programmes. Clin Risk. 2017;135626221770477.

9. Bornman PC, Krige JE, Terblanche J, Rode H, de Villiers JC. Surgery in SA. Arch Surg. 1996;131(1):6-13.

10. Degiannis E, Oettle GJ, Smith MD, Veller MG. Surgical education in SA. World J Surg. 2009;33(2):170-173. Available from: http://dx.doi.org/10.1007/s00268-008-9815-2

11. Kahn D, Pillay S, Veller MG, Panieri E, Westcott MJR. General surgery in crisis: The critical shortage. S Afr J Surg. 2006;44(3):88-94
12. The Higher Risk General Surgical Patient: Towards improved care for a forgotten group - Royal College of Surgeons [Internet]. R Coll Surg. 2017. Available from: https://www. rcseng.ac.uk/library-and-publications/college-publications/ docs/the-higher-risk-general-surgical-patient/.

13. Emergency Surgery: Standards for unscheduled care Royal College of Surgeons. R Coll Surg. 2017. Available from: https://www.rcseng.ac.uk/library-and-publications/ college-publications/docs/emergency-surgery-standards-forunscheduled-care/.

14. Knowing the Risk; a Review of the Peri-operative Care of Surgical Patients. NCEPOD; 2011. Available from: http://www. ncepod.org.uk/2011report2/downloads/POC_fullreport.pdf

15. Spence RT, Zargaran E, Hameed M, Nicol A, Navsaria P. An Objective Assessment of the Surgical Trainee in an Urban Trauma Unit in South Africa: A Pilot Study. World J Surg. 2016 Aug;40(8):1815-22. 